\title{
O Mercado de GaMES: GÊnese, transformações E TENDÊNCIAS
}

\author{
Miriam Costa TOYAMA* \\ Gustavo Mendonça FERRATTI** \\ Mauro Rocha CÔRTES $S^{* * *}$
}

RESUMO: Games fazem parte da indústria cultural multibilionária, possuindo, portanto, relevância econômica e social. Neste ensaio, buscamos realizar uma sociogênese da indústria de games, ancorada nos conceitos de espaço social e campo, a partir de diversos autores, com destaque para Pierre Bourdieu. Com recorte temporal, feito entre os anos 1940 até o momento atual, início da segunda década do século 21, mostramos o fato de que esse espaço social vem sendo reconfigurado, devido às inovações advindas de campos sociais vizinhos, como os da indústria de eletroeletrônicos, informática, telecomunicações e jogos de azar. Tais reconfigurações implicam em rearranjos de posições de agentes, criação de estruturas institucionais e estabelecimento de relações sociais diversas. Por fim, tecemos as considerações pertinentes ao futuro dessa indústria.

PALAVRAS-CHAVE: Indústria de Games. Sociologia Econômica. Espaço Social. Pierre Bourdieu.

\section{Introdução}

O mercado de games é um amplo mercado cultural, como a indústria da música e a cinematográfica (MARCHAND; HENNIG-THURAU, 2013). Em 2019, os jogos digitais geraram US\$152,1 bilhões em receita; quase oito vezes mais do que a indústria

\footnotetext{
* UFSCar - Universidade Federal de São Carlos. Programa de Pós-Graduação em Engenharia de Produção (PPGEP). São Carlos - SP - Brasil. 13565-905 - miriamtoyama@gmail.com. https://orcid.org/0000-00027776-9008.

** UFSCar - Universidade Federal de São Carlos. Programa de Pós-Graduação em Engenharia de Produção (PPGEP). São Carlos - SP - Brasil. 13565-905 - gmferratti@gmail.com. https://orcid.org/00000003-3132-5118.

*** UFSCar - Universidade Federal de São Carlos. Departamento de Engenharia de Produção. Programa de Pós-Graduação em Gestão de Organizações e Sistemas Públicos - PPGGOSP. São Carlos - SP - Brasil. 13565-905 - mauro@dep.ufscar.br. https://orcid.org/0000-0002-6172-0541.
} 
fonográfica com US\$19,1 bilhões (NEWZOO, 2018). Como qualquer mercado, o mercado de games está socialmente enraizado ${ }^{1}$. Sua pertinência para a sociologia econômica (SMELSER; SWEDBERG, 2010) dá-se pelo fato dos seus componentes simbólicos (BOURDIEU, 2005) serem marcadamente importantes em sua dinâmica.

Assim como outras indústrias culturais, a de games tem tensões sobre o que deve ser priorizado no processo de desenvolvimento dos jogos: diversão ou realismo? Acessibilidade ou complexidade? Viabilidade comercial ou mérito artístico? Sendo que grupos sociais distintos defendem diversas maneiras de se pensar os jogos (OAKLEY; O’CONNOR, 2015). Os aspectos culturais dos games de console ${ }^{2}$ são únicos pela sua tradição de englobar, hibridamente, formatos, estilos e conteúdos representativos dos mundos oriental e ocidental (CONSALVO, 2006). A tendência comercial de gamificação - uso da estrutura de jogos no design de outros produtos e serviços ressalta a característica transmidiática da indústria de games, e a força que ela vem conquistado no imaginário social (WALZ; DETERDING, 2015).

Roberts, Arth e Bush (1959) definem jogo como uma atividade de recreação que apresenta as seguintes características: é organizada, competitiva, possui dois ou mais lados, critérios para determinar o vencedor e regras com as quais os participantes concordam, podendo ser divididos entre jogos que demandam habilidade física, jogos de estratégia e jogos de azar. Para os autores, jogos são atividades mais relacionadas à questão da expressividade. Mayra (2008) observa que jogos são objetos de estudos multidimensionais. Watson (2019) afirma que não há consenso quanto à definição de jogo, entretanto, aponta que os trabalhos antropológicos mostram relações entre "jogo e brincadeiras" e entre "jogo e ritual".

Para Watson (2019), os jogos eletrônicos representam um novo desdobramento para o estudo de jogos, tanto em termos de novos espaços quanto em novas regras e dinâmicas entre os jogadores. Entretanto, é importante perceber que os jogos eletrônicos já não cabem na classificação de Roberts, Arth e Bush (1959), uma vez que existem jogos não competitivos e jogos single player (o jogador joga sozinho e ganha se cumprir os critérios do jogo, mas não compete com outros jogadores).

\footnotetext{
1 O conceito proposto por Polanyi (2000) afirma que o sistema econômico está enraizado em relações sociais mais amplas; sendo os mercados apenas um aspecto acessório de estruturas institucionais. Esse conceito tem influenciado grande parte da sociologia econômica contemporânea (JARDIM; CANDIDO, 2019).

2 Um console é um aparelho eletrônico dedicado à execução de games de diversas naturezas, que possui um microcomputador com a função de exercer o papel de central de entretenimento. Diferentemente do PC (computador), costuma não ser utilizado para trabalho e estudo.
} 
Estudos sobre games, oriundos da Geografia Econômica, como os de Balland, De Vann e Boschma (2013), dão ênfase às relações interempresariais com base no território; já os estudos da História, como os de Wolf (2012), atêm-se mais às narrativas factuais; e os estudos da Administração e Economia, como os de Gil e Warzynski (2015), dão ênfase à performance econômico-financeira e à gestão das empresas de jogos. A perspectiva político-cultural utilizada neste ensaio, busca olhar, entre outros aspectos, para a trajetória e para a dinâmica da indústria de consoles, considerando os capitais econômicos e culturais envolvidos e também as disputas centrais, especialmente em torno da tecnologia e dos modelos de negócio, buscando compreender como tais processos condicionam a configuração do mercado.

Analisamos as principais transformações do mercado de consoles, tanto a partir das inovações advindas de campos vizinhos (indústria de eletroeletrônicos, informática, telecomunicações e jogos de azar) quanto de reações sociais adversas, como os boicotes a jogos violentos. Tais situações implicam em desequilíbrios que podem reconfigurar a distribuição de poder entre agentes, bem como alterar a formação e as regras das unidades organizacionais que governam as ações dos agentes. Para esse estudo, não nos dedicamos a identificar os capitais detidos pelos agentes desse espaço.

Em termos técnicos, o ensaio está dividido da seguinte forma: inicia com um breve referencial teórico sobre espaço social e teoria dos campos; em seguida, apresenta uma sociogênese da indústria de games, relacionando-a com os games de consoles; e nas considerações finais, reforça a importância de campos vizinhos para a construção da indústria de games.

\section{Espaço Social e Teoria dos Campos}

Consideramos, como pressupostos, que a agência humana acontece em espaços socialmente referenciados e sua compreensão se dá a partir de recortes mesoanalíticos distintos. Destacamos o conceito de mundos (BECKER; PESSIN, 2006), que foca na questão da cooperação para o desenvolvimento de processos sociais; de campo (BOURDIEU, 2013, FLIGSTEIN; MCADAM, 2012), que se concentra na disputa por capitais assimetricamente distribuídos; das redes sociotécnicas (CALLON,1998), que ressaltam a dimensão tecnológica nas interações sociais; das cités (BOLTANSKI;THÉVENOT,1991), que enfatizam as estruturas mentais de justificação; e dos circuitos sociais (ZELIZER, 2000), que reafirmam o caráter social do dinheiro. Nesse ensaio partiremos da noção de espaço social, de Pierre Bourdieu (2013), buscando 
articulá-la com a ideia de campo (FLIGSTEIN; MCADAM, 2012), entendido aqui, provisoriamente, como um espaço social com maior grau de organização.

As ações e as relações sociais (WEBER, 1999) ocorrem "no" e "ao longo do" tempo e espaço. Espaços sociais podem ser caracterizados como recortes analíticos que circunscrevem ações e relações sociais, contribuindo para a compreensão das estruturas sociais e mentais (BOURDIEU, 2013) presentes nos corpos e nas mentes dos indivíduos e reificados. O ciberespaço (LÉVY, 2010) transforma as relações sociais pela mediação das plataformas digitais.

A ideia de espaço social ressalta a circunscrição da ação individual a uma dimensão maior que o agente, mas inscrita na sociedade. De acordo com Catani (2017, p.177), quando Bourdieu usa o conceito de espaço social está se referindo a um sistema "formado pelo conjunto de posições sociais ocupadas pelos agentes em uma dada formação social". Nesse sentido, as "posições" e as "distâncias" relativas dos agentes na estrutura social são elementos constitutivos da dinâmica do espaço social no qual estão inseridos e que refletem a distribuição dos capitais (e do poder) que os agentes dispõem. Ainda de acordo com Catani (2017), para Bourdieu, os capitais mais determinantes são os culturais e os econômicos. Quanto ao conceito de campo, Bourdieu (2005) considera-o como uma arena, na qual os agentes se encontram e suas ações se desenrolam.

Crossley (2008) trata o conceito de espaço social de forma mais operacional, utilizando uma representação gráfica, na qual uma amostra de indivíduos, supostamente representativa do todo, distingue-se em termos posicionais, em decorrência dos capitais que possuem e mobilizam. No livro Pierre Bourdieu Key Concepts, Thompson (2008) e Crossley (2008) afirmam que, por vezes, Bourdieu trata os conceitos de espaço social e de campo como equivalentes.

Assim, os conceitos de espaço social e campo estão imbricados. Para Fligstein e McAdam (2012), um campo pode ser entendido como um espaço social no qual as relações sociais estão sujeitas a um maior grau de organização, que envolve regras e entendimentos compartilhados. Para Candido et al. (2018), as abordagens de campo explicam a ação a partir de uma concepção relacional. Martin (2003) divide as teorias entre aquelas que circunscrevem a ação a um espaço social denominado "campo" ou "campo organizacional" (DIMAGGIO, POWELL, 2005; LEWIN, 2010) e aquelas mais vinculadas à estratificação e dominação (BOURDIEU, 2005). Candido et al. (2018) consideram a abordagem de Fligstein e McAdam (2012) próxima à de Bourdieu, apesar desta focar mais nos agentes enquanto a primeira foca nas ações coletivas.

DiMaggio e Powell (2005) entendem o isomorfismo entre as organizações como resultado de um campo organizacional que força os agentes a adotarem padrões 
comportamentais considerados corretos e consagrados. Nessa perspectiva, o campo seria um espaço social formado por um conjunto de organizações reconhecíveis que adotam comportamentos similares. Para analisar um campo é preciso entender alguns elementos, entre os quais o próprio campo, os agentes que o compõem, os capitais dos quais dispõem e suas transformações.

Em um determinado campo os agentes podem ser incumbentes, desafiadores ou unidades internas de governança (UIG). Os incumbentes são agentes bem posicionados e com recursos relevantes para as disputas. Os desafiadores tendem a ser menos bem posicionados e possuem menor influência. Já as UIG ajudam o campo a funcionar dentro das regras, facilitando sua reprodução de período a período (FLIGSTEIN; MCADAM, 2012). Essa mesma homologia existe em Pierre Bourdieu (2013), autor para quem todo campo ou espaço social possui dominantes; agentes, que buscam manter as regras existentes no campo ou espaço; os dominados, que sofrem diretamente a violência simbólica dos dominantes e a vanguarda, cujo objetivo é transgredir as regras existentes no campo ou espaço social.

\section{Sociogênese da indústria de games: décadas de 1940 a 1960}

A constituição de um mercado costuma mobilizar inovações ocorridas em espaços sociais ou campos vizinhos (FLIGSTEIN; MCADAM, 2012). Na indústria de games, as inovações vieram das indústrias de eletrônica e de informática, que buscavam alternativas para o uso de uma tecnologia nascente. Nos anos 1940, o aprimoramento dos dispositivos semicondutores e circuitos chaveados (DONOVAN, 2010) propiciou o surgimento dos primeiros jogos em protótipos eletromecânicos, uma bricolagem de botões, LEDs, fios e atuadores. Palola (2016) afirma que não havia qualquer indício da existência de um mercado formal de jogos eletrônicos neste momento, somente ideias que ganhavam forma de maneira orgânica e experimental.

Na década de 1950, com a invenção do tubo de raios catódicos, a tela se consolidou como o principal dispositivo de saída dos aparelhos de jogos eletrônicos, chamados de videogames. Os videogames eram exibidos em grandes feiras de tecnologia, mas inacessíveis para consumo. Suas estruturas eram tão grandes quanto geladeiras e os jogos tão simples quanto "jogo da velha" (DONOVAN, 2010). Na década de 1960, nos EUA, computadores mainframe foram disponibilizados para fins acadêmicos, dando condições para que estudantes universitários ganhassem protagonismo no desenvolvimento de games (HISTORY.COM, 2017). Alguns títulos 
chegaram a ser desenvolvidos por empresas de computadores, mas devido ao alto custo produtivo não atingiam o grande público.

Neste primeiro período, a indústria de games não é mais que um conjunto de agentes dispersos com interesses comuns. Alguns começaram a ganhar certo protagonismo, como as universidades e a Pesquisa, Desenvolvimento e Inovação (PD\&I) de empresas de semicondutores. O que organizava esses agentes era o interesse de criar formas de entretenimento eletrônico, com desafios intelectuais e motores, utilizando as tecnologias emergentes.

\section{Criação e Fortalecimento de um Mercado: década de 1970}

Na década de 1970 estabelece-se o mercado de games através dos arcades ou fliperamas, aparelhos eletrônicos colocados em espaços com alto fluxo de pessoas (por exemplo, bares, restaurantes). As diversões eletrônicas, anteriormente restritas aos acadêmicos e aos entusiastas da tecnologia, tornaram-se parte da cultura pop (JIJI GAHO SHA INC., 2003), de modo que podem ser jogadas em grandes centros urbanos a preço acessível. O modelo de negócio predominante é o aluguel dos arcades para estabelecimentos comerciais, que obtêm lucros por meio da venda de fichas, que dão ao jogador o direito a um certo número de chances, vidas ou tempo de jogo.

Nos EUA, o mercado de jogos domésticos ganhou volume no início da década de 1970. A Magnavox, conhecida pela produção de rádios e televisores, inventou o primeiro videogame: o Magnavox Odyssey (DONOVAN, 2010). Essa invenção forçou seus competidores a tomarem uma posição sobre a entrada ou não nesse novo segmento. A emergente indústria de games construiu um grau de consenso em torno de questões como: a legitimidade dos agentes, as características dos produtos e as regras de troca.

As empresas de eletroeletrônicos, por exemplo, concentraram-se em oferecer produtos que equilibrassem desafio e jogabilidade simples, direcionados a um mercado de luxo. Seu modelo de negócios se baseava em lucrar tanto na venda do console, aparelho que processava os jogos, quanto nas mídias físicas, os jogos em si, vendidos em cartuchos (HARRIS, 2015).

Em meados da década de 1970 surgiram os novos agentes no mercado de games: as empresas japonesas que atuavam no setor de brinquedos e jogos de azar, caso da Nintendo, fabricante do jogo de cartas hanafuda, e da Sega, fabricante de máquinas de caça níquel (HARRIS, 2015); e as empresas estadunidenses que nasceram especializadas em fabricar jogos eletrônicos, como a Atari (PALOLA, 2016). Ao final dos anos 1970, a indústria de games estadunidense passou por sua primeira crise, em 
boa medida decorrente da inovação dos novos entrantes e da fraca proteção da propriedade intelectual. A Magnavox perdeu sua liderança de mercado para a Atari com o lançamento do jogo Pong! e empresas que não estavam bem estabelecidas, como a Coleco, foram à falência (PALOLA, 2016).

Neste período, o mercado funcionava com regras tácitas. A ausência de contratos sociais bem estabelecidos e compartilhados favoreceu as práticas de plágio e engenharia reversa. Os custos dos controles normativos ainda são altos, porém agentes mais hábeis perceberam que a saída para a minimização das perdas passava pela construção de governança.

\section{A Emergência Nipônica: décadas de 1980 e 1990}

No final dos anos 1970 ocorreu uma reconfiguração da indústria de games com empresas estadunidenses que controlavam o mercado, e elas precisaram dividir o espaço com as empresas japonesas. O protagonismo nipônico ficou mais acentuado após 1983, com o lançamento Crash dos Videogames nos Estados Unidos (ou Atari Shock). Vários foram os motivos para tanto, dentre os quais estavam: a saturação do mercado estadunidense, com práticas de plágio e concorrência predatória; a falta de originalidade e baixa qualidade dos jogos; e a migração da comunidade gamer para os computadores pessoais (PCs). Além disso, os impactos econômicos foram significativos, com queda de mais de 70\% nos lucros das empresas estadunidenses no período (ERVIN, 2017).

Nas décadas de 1980 e 1990, as empresas japonesas se tornam dominantes no cenário mundial. A liderança do mercado foi disputada por Nintendo e Sega, nas chamadas terceira (8-bits) e quarta gerações (16-bits) de consoles. Na terceira geração, a disputa ficou entre NES e Master System; e na quarta entre Mega Drive e Super Nintendo (HARRIS, 2015). A Nintendo possuía uma estratégia com forte atuação na proteção à propriedade intelectual, ao rígido programa de licenciamento para terceiros e um amplo controle da distribuição de estoques aos lojistas (HARRIS, 2015). Também oferecia jogos apropriados para toda a família e garantia de qualidade por meio do selo Nintendo.

Já a Sega investiu em uma estratégia mais ousada e oposta à rival. O licenciamento para terceiros era simples, havia muitos jogos com temáticas mais adultas e ampla disponibilidade de produtos no mercado (HARRIS, 2015). Diferentemente da Nintendo, a Sega apostava no sucesso por meio do volume de títulos, gráficos realistas e uma experiência de jogos direcionadas aos jovens e adultos. 
O crescimento do faturamento das empresas acarretou a maior profissionalização do campo, com o aumento dos recursos financeiros necessários para o desenvolvimento de novos consoles, jogos e campanhas publicitárias. A Sega buscou uma imagem de empresa para jovens e adultos, enquanto a Nintendo insistiu no status de empresa com jogos para toda família. Ambas defenderam suas identidades mesmo em momentos de significativas perdas financeiras (ERVIN, 2017).

Ainda na década de 1980, houve a popularização dos videogames portáteis, sendo o mais célebre deles o Gameboy da Nintendo (HARRIS, 2015). Surgiu também a primeira third party ${ }^{3}$ de que se teve notícia: a Activision. As third parties alteraram a dinâmica de fabricação dos games, até então, produzidos exclusivamente pelas mesmas empresas que fabricavam os consoles (HISTORY.COM, 2017). Desde a Activision, os jogos multiplataforma passaram a ser uma possibilidade.

Foi também na década de 1980 que a sociedade civil começou a manifestar sobre os limites da violência nos games, produzindo uma "cruzada moral" contra os jogos violentos (KHALED JR., 2018). A resposta institucional veio somente na década de 1990, com a classificação etária de jogos, que foi introduzida por meio da criação da Entertainment Software Rating Board (ESRB, 2020), uma UIG constituída, até os dias atuais, como um dos principais órgãos reguladores desse espaço social. Khaled Jr. (2018) cita Ronnie Lamm, advogado que perdeu sua licença ao confrontar grandes estúdios de games, como um símbolo da luta civil contra os limites morais dessa indústria.

Em 1992, no ocidente, a Nintendo perdeu sua liderança de mercado para a Sega (HARRIS, 2015), mas outros agentes se mobilizam sinalizando uma ameaça real ao oligopólio Sega-Nintendo. Desses agentes, destacamos: empresas estadunidenses que tentavam se reerguer, como a Atari; empresas japonesas do setor de multimídia, como a 3DO e a Sony (PALOLA, 2016); empresas de eletroeletrônicos que manufaturavam consoles com arquitetura compatível aos produtos das empresas dominantes, como a Gradiente (OMELETE, 2020).

As inovações tecnológicas advindas de campos vizinhos quebraram o oligopólio Sega-Nintendo. Com o lançamento da quinta geração de consoles (32-bit, 64-bit), na "Era 3D", a Sony, empresa japonesa do setor de multimídia, conquistou rapidamente a liderança de mercado. Após negociar sua entrada no setor de games com a Sega e com a Nintendo (HARRIS, 2015), a Sony optou por atuar sozinha, lançando o primeiro console baseado em CDs da história: o Playstation. E como o CD tem valor de reprodução menor do que os cartuchos, então ela conseguiu atingir preços menores em

\footnotetext{
${ }^{3}$ Estúdios que desenvolvem jogos terceirizados para um ou mais fabricantes de consoles.
} 
suas mídias. Além disso, o Playstation era capaz de ler também CDs de áudio e vídeo, o que seria um marco importante na consolidação dos consoles como plataforma de entretenimento.

\section{O Retorno dos EUA: anos 2000}

No início dos anos 2000, o mercado de games domésticos estava dividido entre três grandes agentes: Sony, Nintendo e Sega. Em 2001, entre as disputas da sexta geração de consoles (128 bits), a Sega declarou falência, pouco após o lançamento do seu último videogame, o Dreamcast (PALOLA, 2016). Ela foi comprada pela Sammy Holdings, um conglomerado de entretenimento japonês conhecido por atuar no ramo de pachinko, jogo de azar oriental que misturava os princípios do pinball com os do caçaníquel (HARRIS, 2015). Tal ação de compra pôde ser vista como uma aproximação dos interesses das empresas de jogos de azar com as empresas de games, para além de uma feliz coincidência na gênese do campo ${ }^{4}$.

Após ter sido comprada pela Sammy, a Sega se tornou uma third party, cedendo os direitos dos seus jogos exclusivos (exemplo, Sonic) para outras plataformas, o que a tornou um agente marginal. Entre os motivos da falência da Sega, pode-se destacar: falta de alinhamento estratégico entre a Sega dos Estados Unidos e a do Japão ${ }^{5}$; baixo volume de títulos disponíveis para as últimas plataformas; e falta de competitividade nos preços em relação aos consoles concorrentes (NISHIOKORI, 2019).

No mesmo ano que a Sega faliu, a Microsoft alavancou a participação dos Estados Unidos no mercado de consoles (OMELETE, 2020), lançando o Xbox. O console apresentava um amplo conjunto de inovações tecnológicas, como hardware com maior poder de processamento gráfico e HD embutido de fábrica. Com a entrada da Microsoft no mercado, intensificou-se o movimento de aproximação da indústria de consoles com a de PCs (ERVIN, 2017) que, até então, lidavam com comunidades de jogadores distintas. Em meados dos anos 2000, com a popularização dos serviços de internet banda larga, houve um amplo crescimento dos jogos online (NEWZOO, 2018).

Os jogos multijogadores on-line massivos $(\mathrm{MMOs})^{6}$ rapidamente se popularizaram, tanto nos consoles (e.g. Halo 2) quanto nos PCs (e.g. World of

\footnotetext{
${ }^{4}$ Como já exposto, Sega e Nintendo atuavam nesse setor antes de se tornarem fabricantes de videogames.

${ }^{5}$ Segundo Nishikori (2019), o console Sega Saturn foi lançado no Japão na mesma semana que o Megadrive 32X foi lançado nos Estados Unidos, mas sem comunicação de qualquer um dos lados.

${ }^{6}$ Jogos que permitem múltiplos jogadores simultâneos conectados à internet.
} 
Warcraft). A interconectividade em rede mudou profundamente a interação entre empresa e comunidade de jogadores. A comunidade gamer deixou de ser exclusivamente consumidora de conteúdo e passou a ser produtora. O conteúdo gerado por usuários, avatares e mecanismos de personalização ganharam notoriedade. Para Lemos (2015), tais mecanismos são uma forma de destaque na multidão, pois a experiência dos jogos deixa de ser uma experiência individual ou de pequenos grupos e torna-se uma experiência amplamente coletiva.

Também nos anos 2000, houve um forte crescimento dos jogos para celular, devido à ampliação do acesso aos telefones móveis. Em 2003, o mercado mobile alcançou a mesma popularidade do mercado de consoles no Japão (HERMIDA, 2003). Apple e Google investiram em lojas próprias de jogos virtuais, e hoje em dia, o mercado de jogos para celular supera em valor o mercado de consoles e PC (NEWZOO, 2018).

\section{Presente e Futuro: Microtransações, Streaming e Realidade Virtual}

O mercado de games segue desenvolvendo não apenas novos produtos e serviços, mas também novos modelos de negócios, como as microtransações. Ball e Fordham (2018) definem essas como compras realizadas dentro do jogo que dão acesso a bens virtuais. Já King et al (2019) as definem como a utilização de dinheiro real para a compra de bens virtuais ou moeda fictícia em um game.

As microtransações estão presentes nos mais diversos games e plataformas. Elas constituem a estratégia de fidelização que introduz, periodicamente, no jogo novos conteúdos monetizados. Isso produz a possibilidade de uma experiência de jogo quase infinita em um mesmo título (SCHWIDDESSEN; KARIUS 2018), além de alterar substancialmente o design e o projeto do jogo, que passam a ser entregues ao usuário em "pequenas doses" e reforçam o conceito do jogo como serviço.

Mais recentemente, surgiu um novo tipo de microtransação: as loot boxes. Koeder, Tanaka e Mitomo (2018) e Perks (2019) definem as loot boxes como elementos in-game que possuem mecânicas de jogos de azar. A loot box implica em um elemento de incerteza, pois o jogador não sabe, à priori, quais itens está adquirindo (LATVALA 2018; KING et al 2019). Para Svelch (2017), a maior parte da comunidade de jogadores rejeita as microtransações, desenvolvendo uma série de ações para driblá-las.

O mercado de games continua sendo um oligopólio (MARCHAND; HENNIGTHURAU,2013), com forte imbricamento dos campos de hardware e software, estando segmentado entre: console, PC, dispositivos móveis e jogos para browser. A partir dos anos 2000, observamos o crescimento dos mercados asiáticos e a consolidação da 
Tencent Gant, considerada a maior empresa do mercado. A Tencent Gant é um braço do conglomerado de mídia Tencent, cuja divisão de jogos cresceu através de aquisição e investimento em outras empresas. A empresa é a porta de entrada para o mercado chinês, através de parcerias multilaterais de negócio (GILBERT, 2019).

As empresas mais bem posicionadas têm apostado em novas fronteiras tecnológicas, em geral desenvolvidas em campos vizinhos. Uma delas é o streaming ou cloud gaming, que reforça a ideia de jogo como serviço, dispensando o consumidor de investir em hardware para processamento local, uma vez que necessita apenas de uma boa conexão de internet. Isso permite que a empresa aproveite o "alongamento da cauda", aumentando o número de consumidores com acesso ao jogo (OJALA e TYRVÄINEN, 2011). Outra fronteira tecnológica está nos dispositivos de realidade virtual. Ambas tecnologias têm atraído novos entrantes ${ }^{7}$, com empresas de computação (Nvidia), empresas de telefonia celular (Huawei, HTC e Samsung) e mesmo empresas de mídias sociais (Facebook), como apontam Cyre (2020) e Hood (2020).

\section{Considerações Finais}

Dada a escassez de estudos sociológicos sobre o mercado de games, elaborar um panorama histórico a partir dos principais agentes, tendências, recursos e disputas envolvidas, pareceu-nos um ponto de partida para a abertura de uma agenda de pesquisa. Nesse ensaio buscamos recontar a história desse mercado ancorados nos conceitos de espaço social e campo, ficando evidente a influência de campos vizinhos na criação, no desenvolvimento, na estabilização e desestabilização deste espaço social ao longo de sua trajetória.

Podemos afirmar que o denominado "mercado de games" se estrutura enquanto tal a partir dos anos 1970, com a consolidação dos arcades e dos consoles domésticos e suas mídias físicas. Todavia, esse processo teve início bem antes nos EUA, com o crescimento da indústria eletroeletrônica e da indústria da informática, após a Segunda Guerra Mundial. A combinação do capital econômico dessas empresas com os capitais culturais de pesquisadores e estudantes universitários produziu o amálgama que fez

\footnotetext{
${ }^{7}$ No tocante às atrações de novos entrantes, cabe ponderar também que as situações comportamentais, como as derivadas de cenários decorrentes do COVID-19, reforçam a perspectiva de crescimento deste mercado. Ginak (2020) afirma que o mercado movimentou US\$10 bilhões só durante o mês de março como reflexo do isolamento social da crise da COVID-19. Além disso, Gonzales (2020) afirma que a venda de óculos de realidade virtual disparou no mesmo período devido à necessidade de as pessoas isoladas terem experiências sociais mais imersivas.
} 
surgir a indústria de games, cujo marco costuma ser considerado a invenção do Magnavox Odyssey, por uma empresa que produzia rádios e TVs.

A trajetória da formação desse espaço social envolve a presença de outros agentes, oriundos de campos próximos e detentores de capital econômico. É o caso de empresas de brinquedos e daquelas envolvidas com jogos de azar, além de outras empresas eletroeletrônicas, que perceberam nesse novo produto - nos games - as possibilidades de ampliar seu portfólio comercial. Tais empresas são guiadas pela lógica constitutiva das relações sociais no capitalismo, que legitima como mercadoria tudo o que pode ser precificado.

Nos anos seguintes da formação do mercado de games domésticos, agentes vindos de campos próximos ou da própria indústria de jogos entraram no mercado, como Nintendo e Atari. A primeira grande crise do mercado de games derivou da falta de regulação, que abriu espaço para práticas predatórias ${ }^{8}$, como o plágio sustentado pela engenharia reversa. Isso levou a Magnavox a perder sua liderança, abrindo espaço para entrada de novas empresas, em especial as japonesas, que passaram a dominar o mercado estadunidense. Nos anos 1980 e 1990 veio a consolidação deste espaço através da disputa das duas maiores empresas: SEGA e Nintendo. Ganhou-se destaque um debate sobre qual o nível de violência aceitável em jogos, fato que originou o ESRB Unidade Interna de Governança — que atua para regulamentar as relações através da classificação dos jogos.

A crescente profissionalização exigiu aportes financeiros maiores para o PD\&I e a criação de campanhas publicitárias de massa. Reputação também se configurou como um recurso valioso. A Nintendo reafirma sua posição de empresa familiar e a SEGA se estabelece como uma empresa com jogos para adolescentes e adultos.

Nos anos seguintes, aprofundaram-se a segmentação desse mercado, com jogos para consoles, PCs, dispositivos móveis, portáteis e browsers. A regulação avançou com o reconhecimento de direitos autorais, reduzindo o risco de situações como as que geraram a crise de 1970 .

Inovações em campos próximos seguem levando a disrupções no mercado de games. O desenvolvimento de novas mídias, plataformas e das microtransações está entre as mais importantes. Os modelos de negócios incorporam a dimensão de serviço. As microtransações não substituem, ao menos ainda, a venda de produtos ou o serviço de assinatura. Inovações recentes, que parecem levar ao cloud gaming, reforçam a ideia de jogos como serviço, especialmente em decorrência do alongamento da curva de

\footnotetext{
8 Estamos usando o conceito de concorrência predatória da concepção de controle direito de Fligstein (1993), em que as empresas tomam decisões de negócios agressivas para prejudicar umas às outras.
} 
viabilidade dos negócios. Por outro lado, seguem crescentes as demandas por recursos financeiros para PD\&I, campanhas publicitárias e construção de imagem da empresa.

No que se refere aos conceitos de espaço social e campo, que apresentamos no início deste ensaio, podemos afirmar, provisoriamente, que o mercado de games constitui um espaço social específico, mas não exatamente um campo estabilizado. Entendemos que há ainda muito para se compreender sobre sua dinâmica. Este ensaio, longe de exaurir o objeto, abre portas que nos guiam aos cômodos e vielas que precisam ser investigados.

Apontamos como possibilidades de estudos futuros um aprofundamento na caracterização dos agentes do mercado de games, em especial àqueles envolvidos na cadeia de atividades de desenvolvimento de um game; uma descrição histórica mais detalhada das atividades e contendas presentes ao longo das décadas em que esse mercado vem se desenvolvendo, aqui apenas pinceladas; a compreensão do movimento e suas consequências da crescente aproximação dos games com o campo dos jogos de azar; e a presença dos games em vários campos de ação estratégica, como o cinema e a educação, entre outros. É necessário, enfim, que compreendamos os processos de gamificação da vida social.

\section{The games market: GeNesis, TRANSFORMATIONS AND TRENDS}

ABSTRACT: Games are part of a multi-billion-dollar cultural industry, having economic and social relevance. In this essay, we seek to carry out a sociogenesis of the games industry, anchored in the concepts of social space and field, from different authors, among them, Pierre Bourdieu. Our time frame begins in the years1940s and continues until the present moment, the beginning of the second decade of the 21st century. We show that this social space has been reconfigured from innovations coming from neighboring fields, such as those of the electronics, computer, telecommunications and gambling. Those reconfigurations imply rearranging the positions of agents, creating institutional structures and establishing diverse social relationships. We conclude with considerations about the future of this industry.

KEYWORDS: Games Industry. Economic Sociology. Social Space. Pierre Bourdieu.

\section{EL MERCADO DE LOS JUEGOS: GÉNESIS, TRANSFORMACIONES Y TENDENCIAS}


RESUMEN: Los juegos son parte de una industria cultural multimillonaria, que tiene relevancia económica y social. En este ensayo, buscamos realizar una sociogénesis de la industria del juego, anclada en los conceptos de espacio y campo social, de diferentes autores, con énfasis en Pierre Bourdieu. Nuestro marco temporal comienza en la década de 1940 y continúa hasta el momento actual, inicio de la segunda década del siglo XXI. mostramos el hecho de que este espacio social se ha reconfigurado debido a las innovaciones provenientes de campos sociales vecinos, como la industria electrónica, informática, de telecomunicaciones y de juegos de azar. Esas reconfiguraciones implican la reordenación de las posiciones de los agentes, la creación de estructuras institucionales y el establecimiento de relaciones sociales diversas. Finalmente, tejemos las consideraciones pertinentes al futuro de esta industria.

PALABRAS CLAVE: Industria de los juegos. Sociología económica. Espacio social. Pierre Bourdieu.

\section{REFERÊNCIAS}

BALL, Christofer; FORDHAM, Joseph. Monetization is the Message. Digital Games Research Association. 2018.

BALLAND, Pierre-Alexandre.; DE VAAN, Mathijs.; BOSCHMA, Ron. The dynamics of interfirm networks along the industry life cycle, 1987-2007. Journal of Economic Geography, v. 13, n. 5, p.741-765, 2013.

BECKER, Howard S.; PESSIN, Alain. A Dialogue of The Ideas of "World" and "Field". Sociological Forum. v. 21, n. 2 jun., 2006, p.275-286.

BOLTANSKI, Luc; THÈVENOT, Laurent. On Justification. 1 ed. Paris: Galimard, 1991. BOURDIEU, Pierre. Espaço Físico, espaço social e espaço físico apropriado. Estudos Avançados. v. 27, n. 79, 2013.

BOURDIEU, Pierre. O campo econômico. Política \& Sociedade, v. 4, n. 6, p.15-58, 2005. CALLON, Michel. The Laws of the Market. Oxford: Blackwell Publishers. 1998 CANDIDO, Silvio E. A.; CÔRTES, Mauro R.; TRUZZI, Oswaldo M. S.; SACOMANO NETO, Mário. Campos nos estudos organizacionais. Gest. Prod. 2018, v.25, n.1. p.68-80. 
CATANI, Afrânio Mendes (Org.) Vocabulário Bourdieu. Belo Horizonte: Autêntica Editora, 2017.

CONSALVO, Mia. Console video games and global corporations. New media \& society, v. 8, n. 1, p.117-137, 2006.

CROSSLEY, Nick. Social Class. In: GRENFEEL, Michael. Pierre Bourdieu Key Concepts. Durham: Acumen, 2008. P. 87-100.

CYRE, Clayton. Tencent And Huawei Join For Cloud Gaming. GOG Connect. 2020.

Disponível em: https://bit.ly/358V1UX. Acesso em: 26 abr. 2020.

DIMAGGIO, Paul J.; POWELL, Walter W. A gaiola de ferro revisitada. RAE, v. 45, n. 2, p.74-89, 2005.

DONOVAN, Tristan. Replay: The History of Videogames. Online: Yellow Ant Media. 2010.

ERVIN, Andrew. Bit by Bit: How Videogames Transformed our World. USA: Basic Books, 2017.

ESRB. About ESRB. Disponível em: https://bit.ly/3aw5niL Acesso em: 13 abr. 2020.

FLIGSTEIN, Neil. The Transformation of Corporate Control. USA: Harvard University Press. 1993.

FLIGSTEIN, Neil; McADAM, Doug. A theory of fields. USA: Oxford University Press, 2012.

GIL, Ricard; WARZYNSKI, Frederic. Vertical integration, exclusivity, and game sales performance in the US video game industry. The journal of law, economics, and organization, v. 31, n. suppl_1, p. i143-i168, 2015.

GILBERT, Ben. The biggest game company in the world isn't Nintendo. Business Insider. 2019. Disponível em: https://bit.ly/2VXcqMg. Acesso em: 26 abr. 2020.

GINAK, Letícia. Mercado de Games é Superaquecido com Isolamento Social. Estadão. 2020. Disponível em: https://bit.ly/3dLfMcq. Acesso em: 17 mai. 2020.

GONZALES, Natalia. COVID-19 is a VR gaming boom. The American Genius. Disponível em: https://bit.ly/2VCpjfu. Acesso em: 26 abr. 2020.

HARRIS, Blake J. A Guerra dos Consoles. Rio de Janeiro: Intrínseca. 2015.

HERMIDA, Alfred. Japan leads mobile game graze. BBC news. 2003. Disponível em: http://news.bbc.co.uk/2/hi/technology/3186345.stm. Acesso em: 20 set. 2020.

HISTORY.COM. Videogames History. HC Online. 2017. Disponível em: https://bit.ly/2VSc6y7. Acesso em: 02 mar. 2020.

HOOD, Bryan. The Best VR Headsets to Escape the Real World. 2020. Robb Report. Disponível em: https://bit.ly/357tLpL. Acesso em: 26 abr. 2020. 
JARDIM; Maria Chaves; CANDIDO, Silvio Eduardo Alvarez. A sociologia econômica nos Estados Unidos: principais autores, conceitos e debates. Revista Brasileira de Informação Bibliográfica em Ciências Sociais - BIB, n. 88, 2019.

JIJI GAHO SHA INC. Asia-Pacific Perspectives, v.1. Hakubundo: Japan Publications. 2003.

KHALED JR.; Salah H. Videogame e violência. Rio de Janeiro: Civilização Brasileira. 2018.

KING, Daniel L.; RUSSEL, Alex M.T; DELFABRO, Paul H.; POLISENA, Dean. Fortnite microtransaction spending was associated with peers' purchasing behaviors but not gaming disorder symptoms. Addictive Behaviors. 2019. Doi: 10.1016/j.chb.2019.07.017

KOEDER, Marco J.; TANAKA, Ema; MITOMO, Hitoshi. Lootboxes in digital games. 22nd Biennial Conference Of the ITS. Seul: EconStor. 2018.

LATVALA, Tatu. Elements of Gambling in Video Game Microtransactions. Jyväskylä: University of Jyväskylä Press. 2018.

LEMOS, André. Cibercultura. Porto Alegre: Sulina. 2015;

LÉVY, Pierre. Cibercultura. São Paulo: Editora 34, 2010.

LEWIN, Kurt. Resolving Social Conflicts. Kindle Edition: 2010

MARCHAND, André; HENNIG-THURAU, Thorsten. Value Creation in the Video Game Industry. Journal of Interactive Marketing. n.3, v. 27, jan. 2013.

MARTIN, John L. What is a field theory? American Journal of Sociology. n.109, v.1, p.1-49. 2003.

MAYRA, Frans. An introduction to game studies. Los Angeles: Sage. 2008.

NEWZOO LTD. Annual Global Games Market Report 2018. Disponível em: https://bit.ly/2S30yqC. Acesso em: 29 fev. 2020.

NISHIKORI, Igor. Sega - 59 anos. TechTudo. 17 jul. 2019. Disponível em: https://glo.bo/3281srh Acesso em: 15 abr. 2020

OAKLEY, Kate; O'CONNOR, Justin. (Ed.). The Routledge companion to the cultural industries. Routledge, 2015.

OJALA, Arto e TYRVÄINEN, Pasi. Value network in cloud computing. Journal of Business Strategy, 2011. Disponível em:

https://www.researchgate.net/publication/239781200_Value_networks_in_cloud_computing. Acesso em: 15 ago. 2020.

OMELETE ORIGINAIS. Destravado. Disponível em: https://bit.ly/2VVkFsd. Acesso em: 13 abr. 2020.

PALOLA, Taneli. History of Videogames. VGChartz. 2016. Disponível em: https://bit.ly/2KoKuvk. Acesso em: 23 abr. 2020. 
PERKS, Mathew E. How Does Games Critique Impact Game Design Decisions? A Case Study of Monetization and Loot Boxes. Games and Culture, p. 1-22, 2019.

POLANYI, Karl. A Grande Transformação. 2 ed. Rio de Janeiro: Compus. 2000.

ROBERTS, John M.; ARTH, Malcolm J. e BUSH, Robert R. Games in Culture. American Anthropologist, v. 61, n.4, p.597-605, 1959. Disponível em: https://bit.ly/3jrUqUo. Acesso em: 15 jul. 2020.

SCHWIDDESSEN, Sebastuab; KARIUS, Philipp. Watch your loot boxes. Interactive Entertainment Law Review, v. 1, n. 1, p.17-43, 2018.

SMELSER, Neil J.; SWEDBERG, Richard. The handbook of economic sociology. Princeton UP, 2010.

SVELCH, Jan. Playing with and against Microtransactions In: MCCAFFREY, Matthew. The evolution and social impact of videogame economics. Londres: Lexington Books, 2017. p.201-120.

THOSOM, Patricia. Field. In: GRENFEEL, Michael. Pierre Bourdieu Key Concepts. Durham: Acumen, 2008. p. 67-84.

WALZ, Steffen P.; DETERDING, Sebastian (Ed.). The gameful world: Approaches, issues, applications. Mit Press, 2015.

WATSON, Max. Games. Cambridge encyclopedia of anthropology. 2019. Disponível em: https://bit.ly/32vhNVW. Acesso em: 16 jul. 2020.

WEBER, Max. Economia e sociedade. v. 1. Brasília: UnB, 1999.

WOLF, Mark J. Before the crash. Wayne State University Press, 2012.

ZELIZER, Viviana. The purchase of intimacy. Law \& Social Inquiry, v. 25, n. 3, p.817-848, 2000 .

Recebido em 05/03/2020.

Aprovado em 18/09/2020. 